\title{
Measuring scheme for determination of loads acting on the side frame of the bogie from a wheelset
}

\author{
Rustam Rahimov ${ }^{1 *[0000-0002-5652-2604]}$, Anastasia Nekrasova $^{2}$, Larisa Ogorodnikova ${ }^{2}$, Grigory \\ Lisovsky $^{2}$, Dilfuza Zairova ${ }^{1}$, and Guldora Mustaeva ${ }^{1}$ \\ ${ }^{1}$ Tashkent State Transport University, Tashkent, Uzbekistan \\ ${ }^{2}$ Emperor Alexander I St. Petersburg State Transport University, Moscow
}

\begin{abstract}
The study aims to develop a measuring circuit to determine the loads acting on the side frame of the bogie from the wheelset when the wagon is moving. The paper reviews and analyzes experimental methods for measuring the vertical and lateral forces acting on the side frame of the bogie from the wheelset when the wagon is moving. Theoretical studies of the stress-strain state of the side frame of a freight wagon bogie were carried out using the finite element method under the action of loads on the axle opening from the wheelset. As a result of theoretical studies by the finite element method, the places for the installation of strain gauges were determined, and a method for processing the received signals was selected. The developed measuring scheme makes it possible to determine the spatial force effect acting on the side frame of the bogie from the wheelset, which makes it possible, without increasing the number of measuring channels in the equipment, to reduce the number of strain gauges for measuring the considered loads while running dynamic tests. In addition, it improves the accuracy of measurements of vertical loads, with the help of which the coefficient of dynamic addition of unsprung parts of the bogie is calculated.
\end{abstract}

\section{Introduction}

When conducting field trials of freight wagons, it is important to determine their dynamic qualities accurately, which are determined by the calculation-empirical method [1-4]. Among the indicators of the dynamic qualities of wagons, one can single out the coefficient of dynamic addition of unsprung parts and frame forces (figure 1) [5-6]. These indicators are calculated through the values of the vertical and lateral loads acting on the side frame of the bogie from the wheelset and are used to calculate the safety factors against wheel derailment and overturning stability, which is directly related to safety issues during the movement of rolling stock [7-9]. 


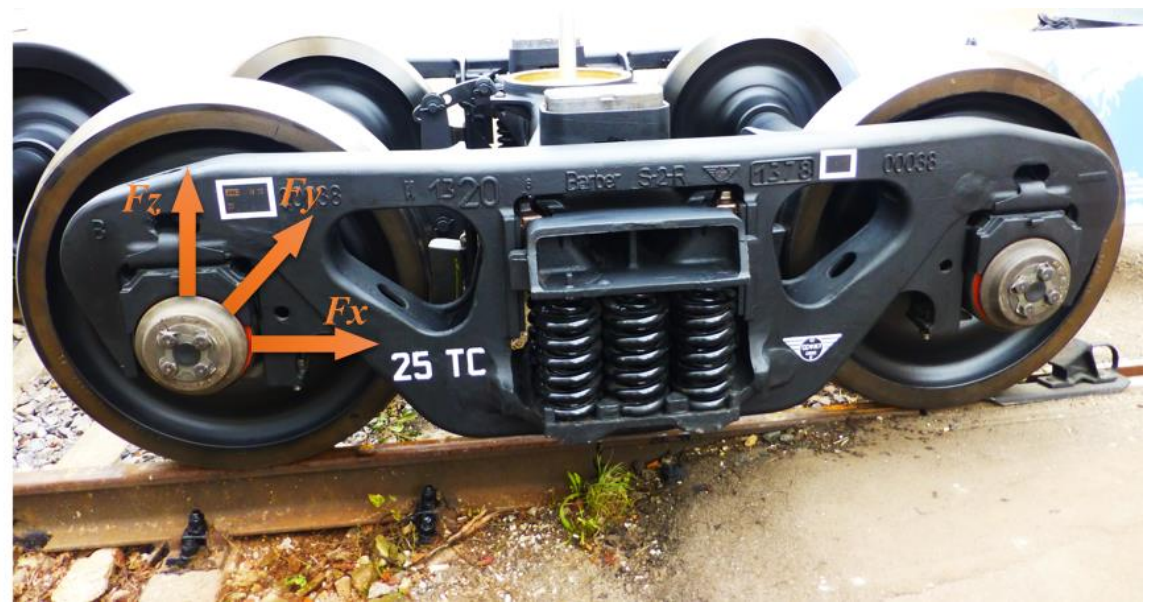

Fig.1. Loads acting on the side frame of the bogie from the wheelset when the wagon is moving: $F_{z}$ are loads acting in the vertical direction; $F_{y}$ are loads acting in the lateral direction; $F_{x}$ are loads acting in the longitudinal direction.

\section{Methods}

At present, the measuring circuit for determining the vertical dynamic loads acting on the bogie bolster, strain gauges are glued in sections A-A and C-C near the side skids and in the middle section B-B of the bogie bolster (figure 2). At the same time, to exclude false signals associated with the expansion of the structure material when its temperature changes during testing, in section $\mathrm{B}-\mathrm{B}$, strain gauges $1^{\prime}$ and $2^{\prime}$ are connected to a bridge circuit with two compensation strain gauges $K_{1}$ and $K_{2}$. In sections $A-A$ and $C-C$ of the bogie bolster, temperature compensation is achieved by switching on strain gauges on compressed (strain gauges 1-2) and stretched (strain gauges 3-4) fibers in different arms of the bridge circuit [2].
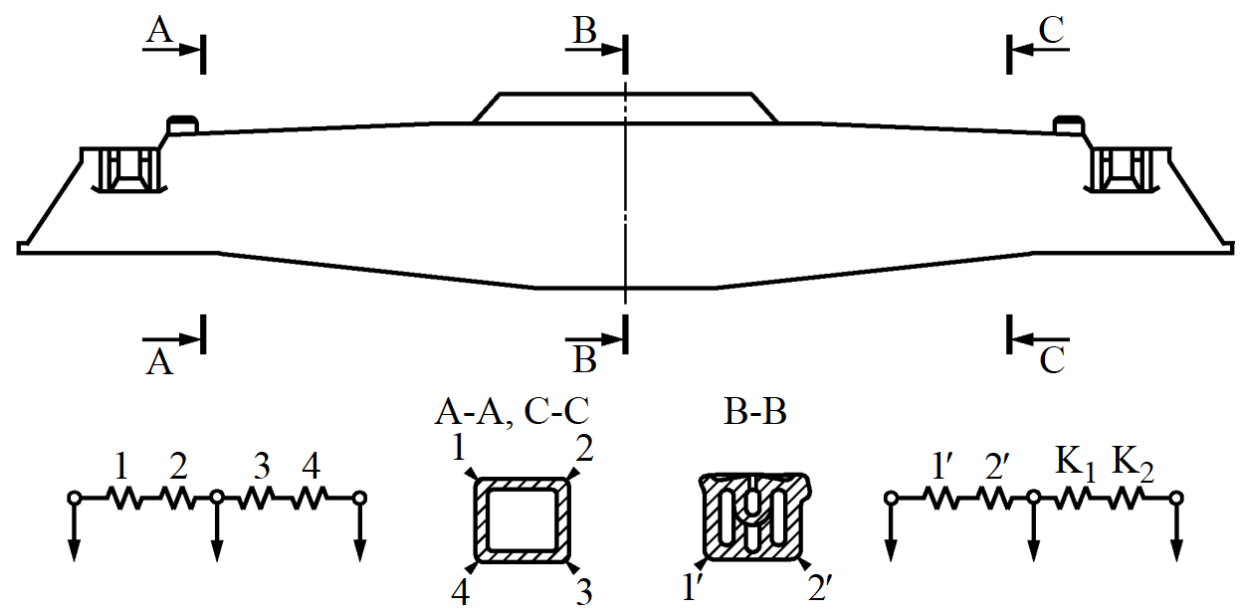

Fig2. Scheme of installation and connection of strain gauges for measuring the vertical force on the bogie bolster. 
This scheme for measuring the vertical dynamic force, based on measurements of deformations on the bogie bolster, is currently included in the normative and technical documentation GOST 33788-2016 [10] to determine the coefficient of dynamic addition of sprung parts of a freight wagon bogie.

In works $[1,11]$, it is noted that with such schemes of connection of strain gauges, deformations of the bolster of the bogie are recorded only from vertical loads. Deformations from lateral loads with such connection schemes of strain gauges are not recorded, and therefore, they do not affect the accuracy of measuring deformations from vertical dynamic forces.

According to GOST 33788-2016 [10], the vertical dynamic force measurement scheme, which is used to calculate the coefficient of dynamic addition of unsprung parts of the bogie, consists of two active strain gauges 1-2, installed on the surface of the radius formed by the transition zone from the upper chord of the side frame to the inclined chord in sections $\mathrm{A}-\mathrm{A}$ and $\mathrm{B}-\mathrm{B}$ (figure 3), and two compensation strain gauges $\mathrm{K}_{1}$ and $\mathrm{K}_{2}$.

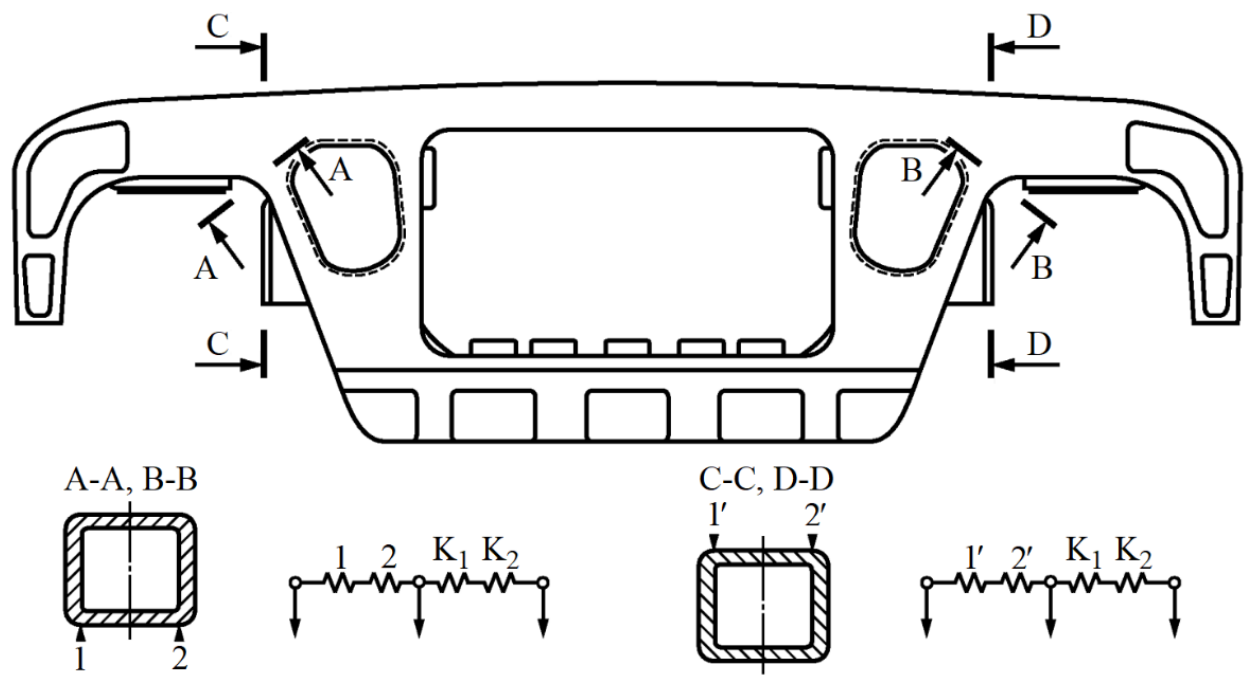

Fig.3. Diagram of installation and connection of strain gauges for measuring vertical force on the side frame of the bogie.

In practice, the measurement scheme used by test centers is also allowed $[12,13]$, where active strain gauges $1^{\prime}$ and $2^{\prime}$ (figure 3 ) are placed on the upper outer part of the upper chord of the side frame over the radius formed by the transition zone from the upper chord to the inclined chord of the side frame in sections C-C and D-D and are connected to a bridge circuit with two compensation strain gauges $\mathrm{K}_{1}$ and $\mathrm{K}_{2}$.

There is also a known method for measuring vertical forces, described in $[1,11,14]$, which includes the installation of two strain gauges: active (1), compensation (2), on the upper outer part of the upper belt of the side frame, in the over-axial zone, in the section of the vertical inner jaw guide, T-shaped (figure 4, $a$ ) concerning each other or in the form of a cross (figure $4, b$ ). In this case, the active strain gauge is installed along the fibers, and the compensation one - across the fibers. Both strain gauges are connected in series with each other in an external half-bridge with active and compensation strain gauges [1].

Studies $[15,16]$ show that these measurement schemes are sensitive to the action of transverse and longitudinal forces from wheelsets on the side frame of the bogie; therefore, 
they do not allow determining its value with sufficient accuracy. The error in determining the vertical force can exceed $50 \%$.

In [16] $\mathrm{V}$ F Ushkalov, Yu S Romen, A V Zavertalyuk and others consider the correctness of the strain gauge schemes used during dynamic tests of freight wagons for registering the coefficient of vertical dynamic additives for unsprung bogie masses. To exclude the influence of longitudinal forces when measuring vertical forces, the authors propose to install strain gauges at four points of the upper belt of the side frame of the bogie in the section of the vertical internal jaw guide. However, in [15], it was determined that when measuring vertical forces, such a scheme can compensate only for the influence of lateral forces. The scheme does not allow to sufficiently exclude the influence of longitudinal forces. Subsequently, the method for measuring vertical forces was improved in $[14,17]$.

$a$

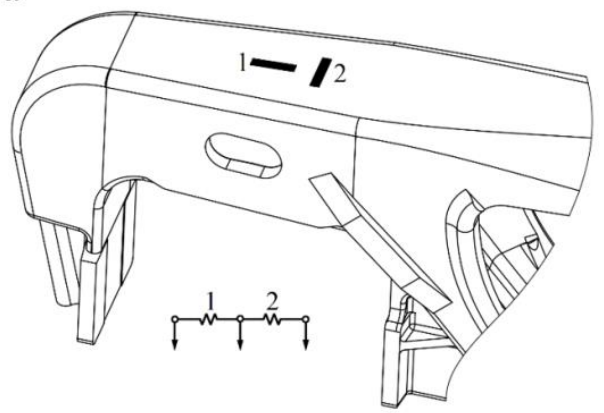

$b$

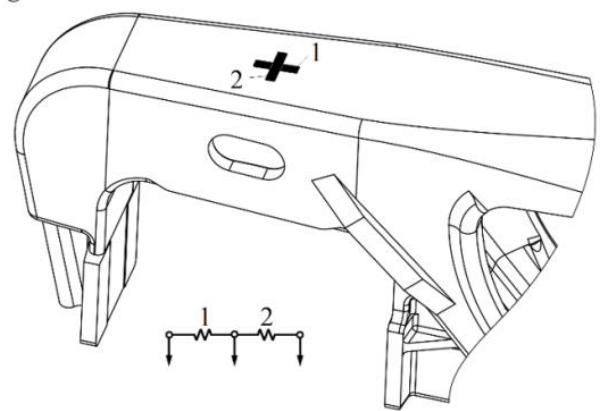

Fig. 4. Diagram of installation and connection of strain gauges for measuring vertical force on the side frame of the bogie.

In [14], the authors V F Ushkalov, S A Kostritsa, A V Sultanov and others, based on studies of the loading of the side frame of the bogie by the finite element method, proposed a new measuring scheme, which makes it possible to significantly reduce the effect of longitudinal and transverse forces. The recommended places for the installation of strain gauges on the side frame of the bogie were determined, in which there is a minimal effect of the above factors (figure 5).

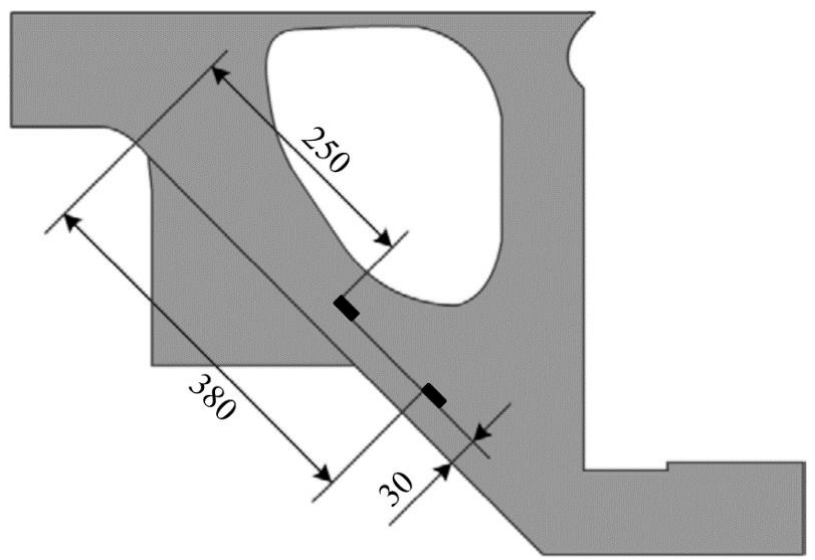

Fig. 5. Installation diagram of strain gauges on the side frame of the bogie. 
To eliminate the influence of lateral loading, it is proposed to glue four strain gauges on an inclined zone on both sides of the side frame at an angle of $45^{\circ}$ to the horizon and connect them to one complete Wheatstone bridge so that signals proportional to deformations from vertical forces are added up, and deformations from transverse forces were deducted and compensated for each other. According to the results of calculating the deformations under the action of a lateral force, their value, taking into account the inclusion of two strain gauges in different branches of the measuring bridge, as noted by the authors of the work, should not exceed $12 \%$ of the deformations caused by the action of vertical loads.

In work [18] by the authors, A V Belyankin, A I Konovalov and D N Dorokhin proposed to install strain gauges 1-2 (figure 6) on the upper outer part of the upper belt of the side frame above the technological opening, in places that are insensitive to the action of longitudinal and transverse horizontal forces. To eliminate the influence of the lateral force, strain gauges are proposed to be installed from different edges in places where the deformations are the same in magnitude and different in sign.

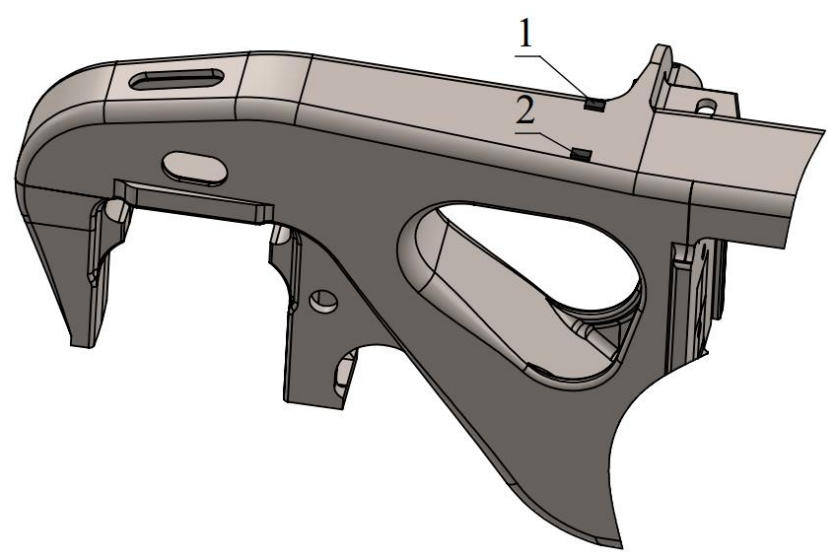

Fig. 6. Installation diagram of strain gauges on the side frame of the bogie.

In [6], the authors determined that due to the placement of the triangle suspension bracket on the inner surface of the frame, the line where the stresses from the action of lateral forces change sign and are approximately equal to zero, and are also insensitive to the action of longitudinal forces, does not pass through the middle, but is located on some distance (1) from it (figure 7). Therefore, the placement of two strain gauges on the upper outer part of the upper zone of the side frame symmetrically relative to the middle of the side frame of the bogie can introduce an error in the measurement of the vertical force. In this case, the distance 1 is specified by calculation depending on the specific design of the side frame of the bogie. Consequently, to improve the method considered in [18], it was proposed to install one on the line instead of two strain gauges on the upper outer part of the upper zone of the side frame above the technological opening, where the stresses from the action of lateral forces change sign and are equal to zero, and are also insensitive to the action of longitudinal forces. 


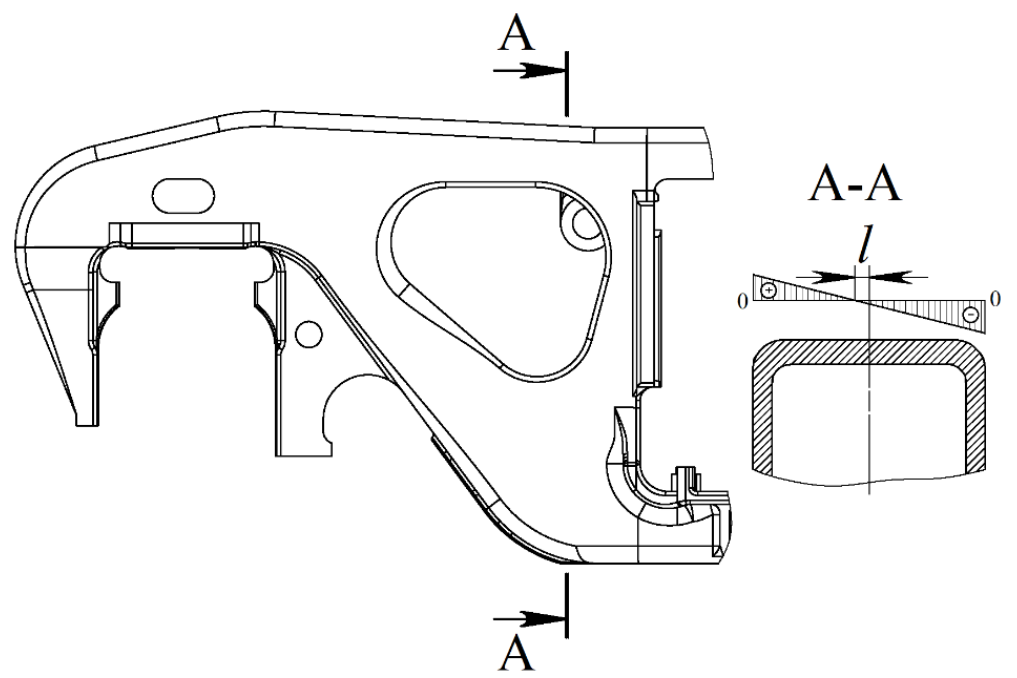

Fig.7. Diagram of the distribution of normal stresses along the upper outer part of the upper chord of the side frame of the bogie from the action of longitudinal and lateral forces.

The scheme for measuring the lateral (frame) force during testing of a freight wagon consists of eight strain gauges installed on both sides on the upper and inclined chords of the side frame of the bogie [1, 2, 11]. In this case, strain gauges 1-4 (figure 8) are located on the side of the upper chord of the side frame, above the technological window, strain gauges 5-8 - on an inclined chord under the technological window. Such a scheme for measuring the lateral dynamic force, based on measurements of deformations on the side frame of the bogie, is currently included in the normative and technical documentation GOST 33788-2016 [10] to determine the value of the lateral (frame) force.

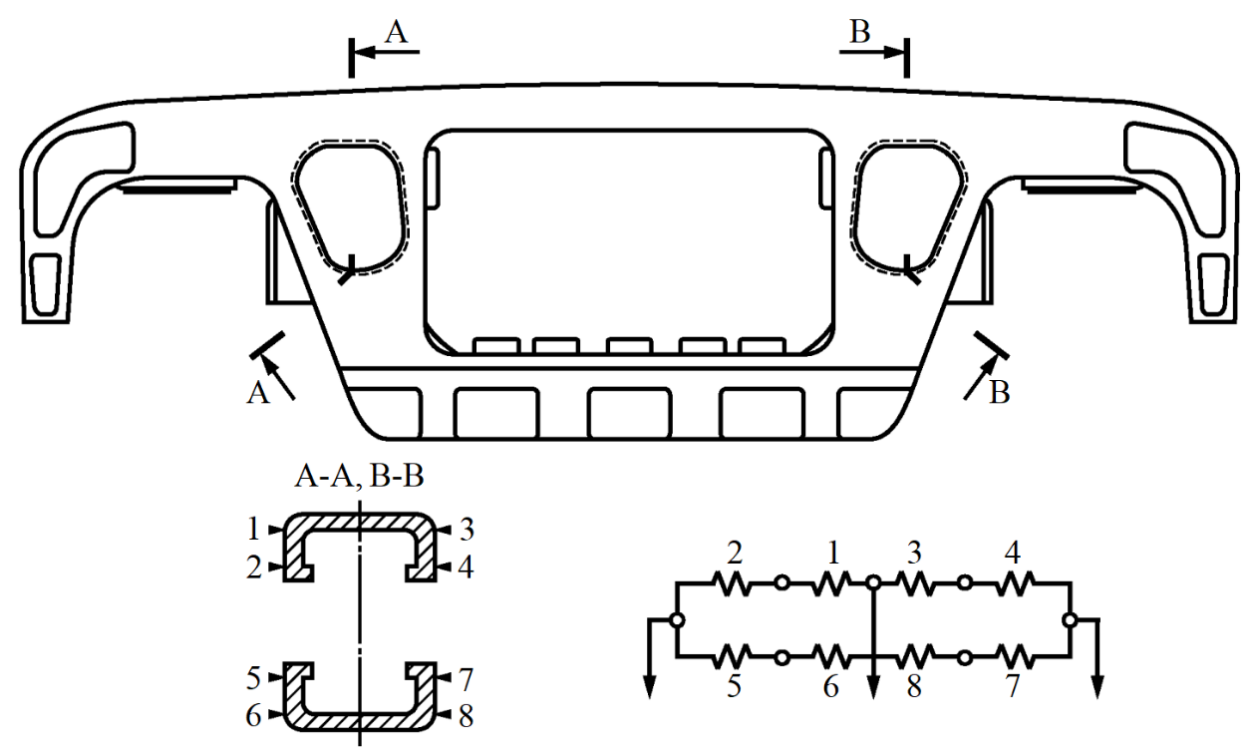

Fig. 8. Scheme of installation and connection of strain gauges for measuring the lateral (frame) force on the side frame of the bogie. 
In work [1] to determine the frame force acting from the wheels on both side frames of the bogie, Anisimov proposes to combine the connection diagrams of strain gauges on each side frame of the bogie into a single measuring circuit. In this case, algebraic summation occurs, taking into account the plus and minus signs of the acting frame forces on the individual side frames of the bogie.

The performed studies $[5,6,13,19]$ show that the existing schemes for measuring the vertical and lateral loads acting on the side frame of the bogie from the wheelset do not allow determining their values with sufficient accuracy. With the simultaneous action of several forces, the existing measuring circuits do not fully compensate for the influence of additional loads arising from movement in curved track sections and on switch turnouts. It is also not possible to determine the numerical values of the longitudinal loads.

\section{Results and Discussion}

Taking into account the shortcomings of the existing measuring circuits and to find new places for installing strain gauges and a method for processing the received signals, which makes it possible to determine the values of vertical, longitudinal and lateral (frame) loads with sufficient accuracy, theoretical studies of the stress-strain state of the side frame of a freight wagon bogie [20] were carried out using the finite element method under the action of loads on the axle opening from the wheelset. The study took into account the effect of the spatial loading of the side frame of the bogie.

As a result of calculations using the finite element method, the obtained diagrams of the distribution of normal stresses along the longitudinal axis on the side frame of the bogie, caused separately by longitudinal and separately lateral forces, as well as their joint action, are shown in figure 9.

As a result of the analysis of the diagrams of the distribution of normal stresses (along the longitudinal axis) arising on the side frame of the bogie under the action of vertical, longitudinal and lateral forces, it was found that the most promising is the placement of four strain gauges 2 (figure 10) on the upper outer part of the upper chord of the side frame 1 in the area between the jaw guides, which limit the movement of the wheelset.

a

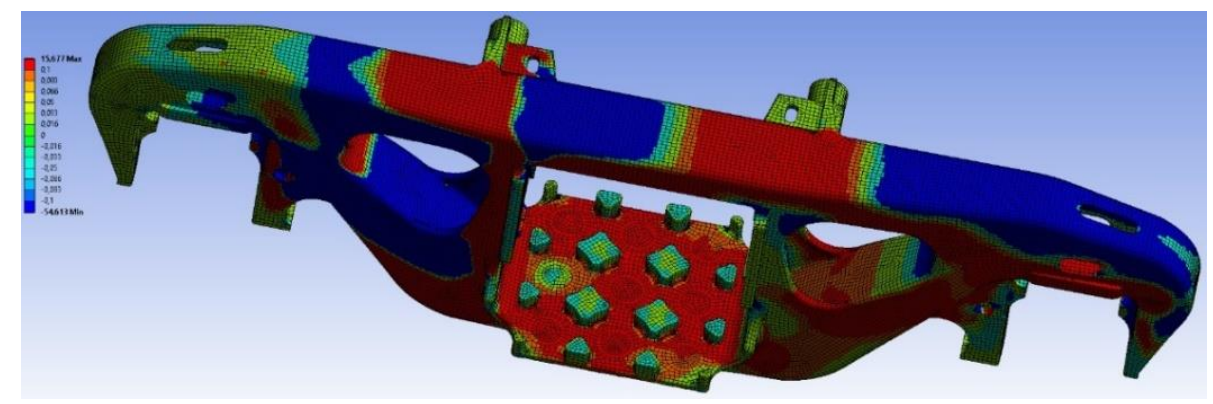


$b$

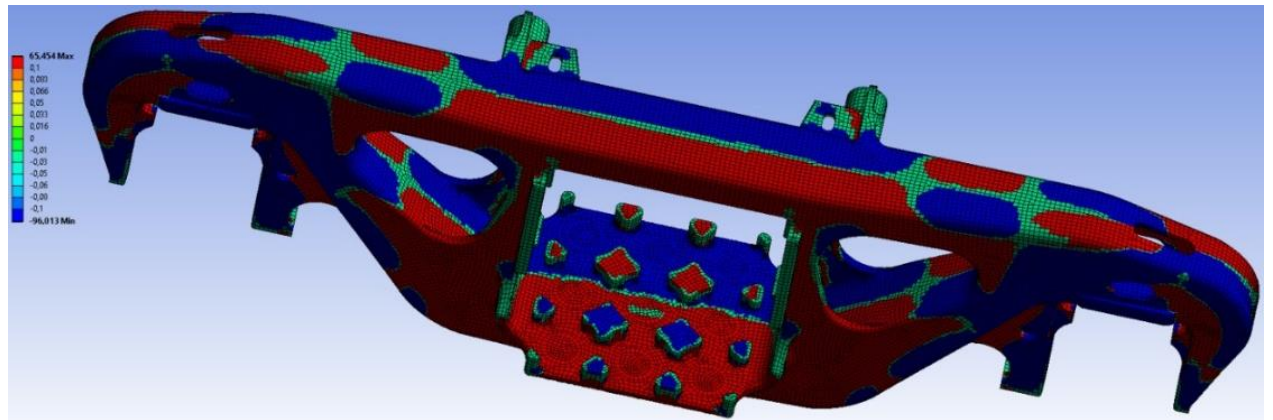

$c$

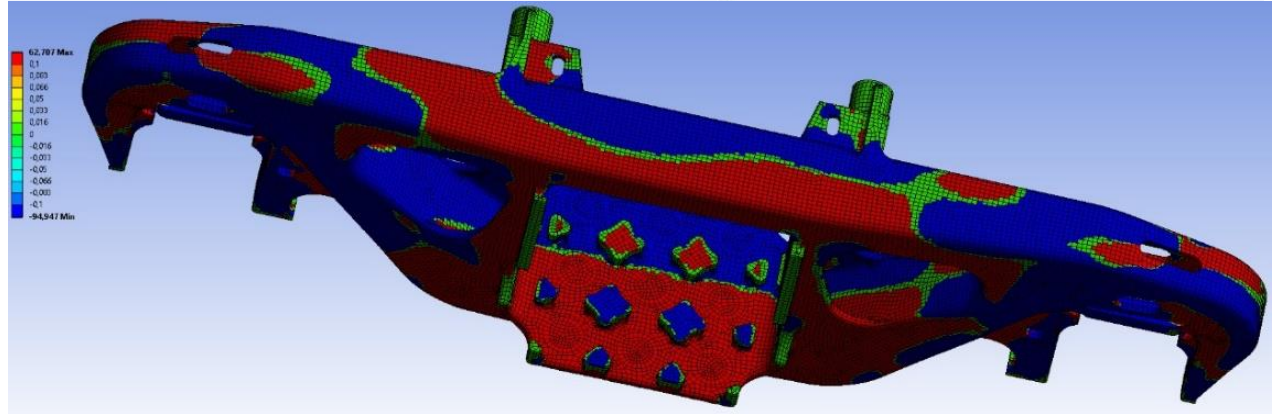

Fig. 9. Diagram of the distribution of normal stresses on the side frame of a freight wagon bogie from the action of the longitudinal force $(a)$, the lateral force $(b)$ and the simultaneous action of the lateral and longitudinal forces $(c)$.

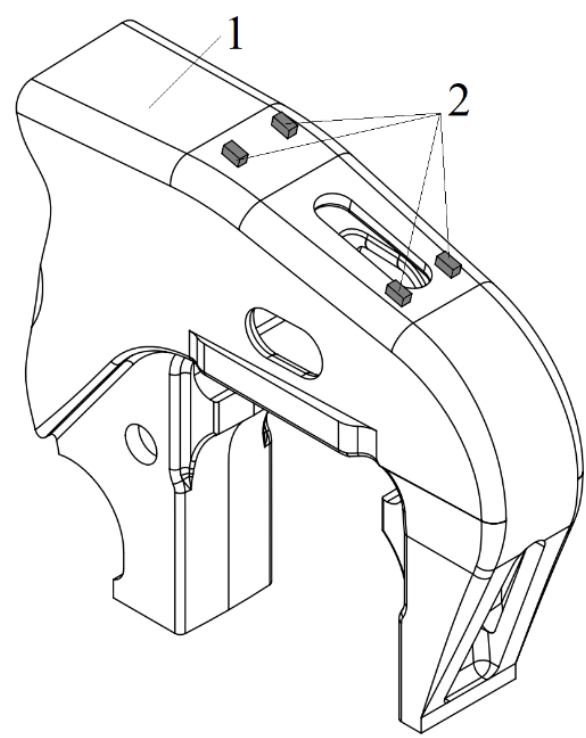

Fig.10. Scheme of installation of strain gauges on the side frame of a freight wagon bogie.

In this case, two strain gauges 1 and 2 (figure 11) are located in section I-I of the vertical inner jaw guide, and two other strain gauges 3 and 4 are located in section II-II of the vertical outer jaw guide. 
To obtain the output signals, strain gauges $R_{1} \ldots R_{4}$ (figure 12) are connected into four measuring bridges, and each measuring bridge contains one working strain gauge and three compensation strain gauges $\mathrm{K}$, which are connected to the recording devices through strain amplifiers.

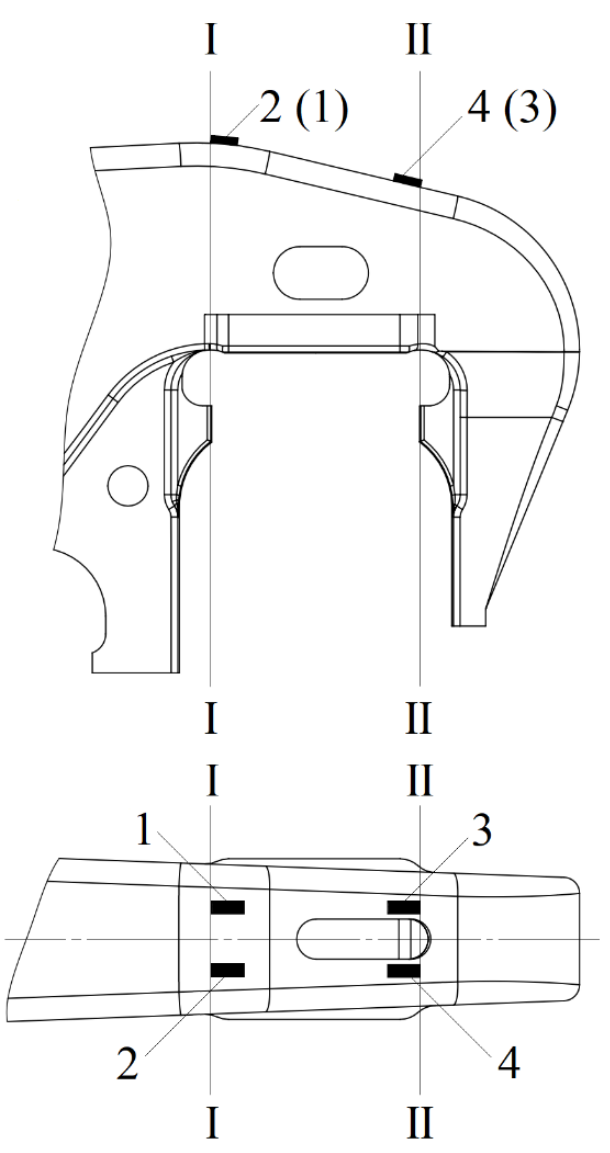

Fig.11. Installation diagram of strain gauges on the side frame of a freight wagon bogie.

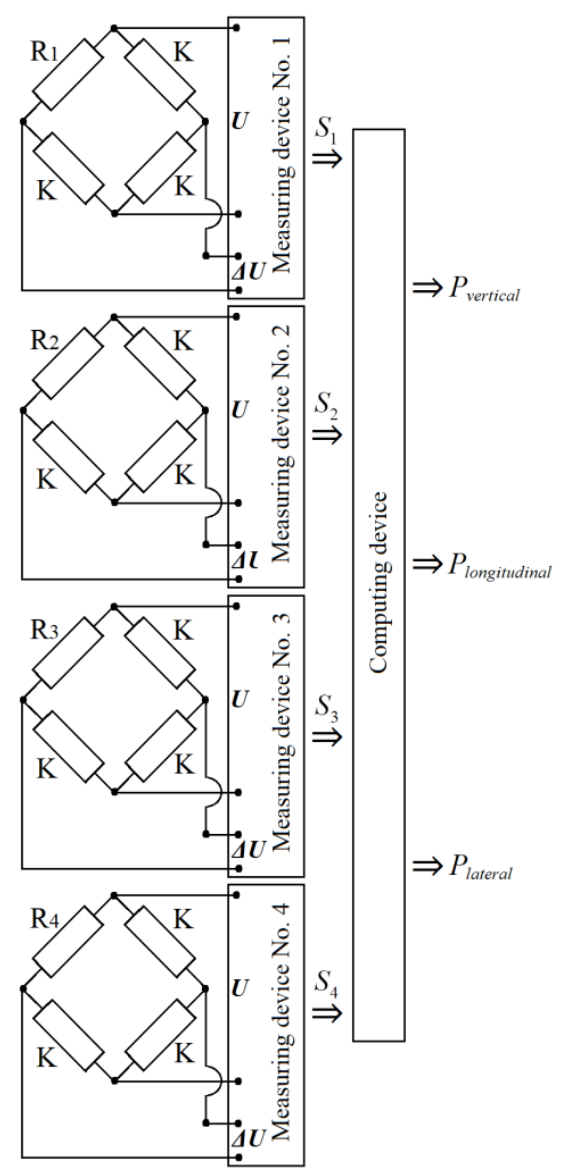

Fig.12. Connection diagram of strain gauges in four measuring bridges.

Signals from the installed strain gauges are processed using the pseudoinverse matrix $[\mathrm{G}]+$, the constant coefficients of which are compiled when carrying out calibration loads and are used to restore the values of the forces acting on the side frame of the bogie from the wheelset.

As a result, the restoration of the values of the vertical force $P_{\text {vertical }}(t)$, the longitudinal force $P_{\text {longitudinal }}(t)$ and the lateral (frame) force $P_{\text {lateral }}(t)$ according to the incoming signals of the strain gauges at each moment of time are calculated using the following mathematical formulas: 


$$
\begin{gathered}
\left\{P^{\prime}(t)\right\}=\left\{\begin{array}{c}
P_{\text {vertical }}(t) \\
P_{\text {longitudinal }}(t) \\
P_{\text {lateral } 1}(t) \\
P_{\text {lateral } 2}(t)
\end{array}\right\}=[G]^{+} \cdot\{S(t)\}=\left[\begin{array}{llll}
a_{11} & a_{12} & a_{13} & a_{14} \\
a_{21} & a_{22} & a_{23} & a_{24} \\
a_{31} & a_{32} & a_{33} & a_{34} \\
a_{41} & a_{42} & a_{43} & a_{44}
\end{array}\right] \cdot\left\{\begin{array}{l}
S_{1}(t) \\
S_{2}(t) \\
S_{3}(t) \\
S_{4}(t)
\end{array}\right\} ; \\
\{P(t)\}=\left\{P^{\prime}(t)\right\}^{T} \cdot[W]=\left\{P_{\text {vertical }}(t), P_{\text {longitudinal }}(t), P_{\text {lateral } 1}(t), P_{\text {lateral } 2}(t)\right\} \cdot\left[\begin{array}{lll}
1 & 0 & 0 \\
0 & 1 & 0 \\
0 & 0 & 1 \\
0 & 0 & 1
\end{array}\right],
\end{gathered}
$$

Here $P_{\text {vertical }}(t)$ is the vertical force acting on the side frame of the bogie from the wheelset at the required time; $P_{\text {longitudinal }}(t)$ is longitudinal force acting on the side frame of the bogie from the wheelset at the required time; $P_{\text {lateral }}(t)$ is lateral force arising during simultaneous vertical and longitudinal loading; $P_{\text {lateral }}(t)$ is lateral force arising from simultaneous vertical loading; $a_{11} \ldots a_{44}$ are constant coefficients included in the pseudoinverse matrix $[\mathrm{G}]^{+} ; S_{1}(t), S_{2}(t), S_{3}(t), S_{4}(t)$ are output signals of strain gauges at the required time; $P^{\prime}(t)$ is the vector of registered forces in the side frame of the bogie; $P^{\prime}(t)^{T}$ is transposed vector of registered forces in the side frame of the bogie; $[W]$ is a summation matrix that allows summing up some forces recovered during diagnosis to determine their actual value.

The performed studies of the stress-strain state of the side frame of a freight wagon bogie using the finite element method under the action of loads from a wheelset showed that such an arrangement of strain gauges and a method for processing the received signals provide measurements of vertical, longitudinal and lateral loads with sufficient accuracy.

\section{Conclusions}

Thus, based on the performed theoretical studies, the locations of the strain gauges installation and the method of processing the received signals have been determined, which makes it possible with sufficient accuracy to determine the spatial force effect acting on the side frame of the bogie from the wheelset while running dynamic tests of wagons. It was found that the developed measuring scheme allows one to determine the spatial force effect acting on the side frame of the bogie from the wheelset, which makes it possible, without increasing the number of measuring channels in the equipment, to reduce the number of strain gauges for measuring the considered loads while running dynamic tests.

According to the developed device and method for measuring the vertical, longitudinal and lateral forces acting on the side frame of the bogie from the axle box unit when the wagon is moving, a patent for the invention was obtained.

\section{Acknowledgements}

This work was carried out with the support of the Federal State-Funded Educational Institution of Higher Professional Education "Emperor Alexander I St. Petersburg State Transport University" of initiative scientific works carried out by student science teams. 


\section{References}

1. Anisimov P S, Testing of wagons. Monograph (Moscow: Marshrut) p 197. (2004)

2. Vershinskiy S V, Danilov V N, Khusidov, V D, The dynamics of a wagon (Moscow: Transport) p.360, (1991)

3. Iwnicki S D, Stichel S, Orlova A, Hecht M. Dynamics of railway freight vehicles Vehicle System Dynamics. 53. (7) pp 995-1033. (2015)

4. GOST 33211. Freight wagons. Requirements to structural strength and dynamic qualities (Moscow: Standartinform) p 54. (2014).

5. Boronenko $\mathrm{Yu}$ P, Rahimov R V. Experimental determination of vertical and lateral loads on the bogie side frame of a freight wagon Proc. XII Int. Scientific Conf. «Transport Problems 2020» (Katowice: Silesian University of Technology Faculty of Transport and Aviation Engineering) pp 72-81. (2020)

6. Boronenko Yu P, Rahimov R V, Belyankin A V, Developing new methods for measuring vertical forces acting on the bogie side frame from the wheelset of a moving wagon, Proceedings of Petersburg Transport University 17. (1) pp 7-22. (2020)

7. Wilson $\mathrm{N}, \mathrm{Wu} \mathrm{H}$, Klopp A, Keylin A, Railway vehicle derailment and prevention Handbook of railway vehicle dynamics ed. S Iwnicki, M Spiryagin, C Cole, T McSweeney (Boca Raton: CRC Press) chapter (11) p 373. (2019)

8. Wilson N, Fries R, Witte M, Haigermoser A, Wrang M, Evans J, Orlova A. Assessment of safety against derailment using simulations and vehicle acceptance tests, a worldwide comparison of state-of-the-art assessment methods Vehicle System Dynamics. 49. (7) pp 1113-1157. (2011)

9. Durali M, Jalili M M, A new criterion for assessment of train derailment risk Proceedings of the Institution of Mechanical Engineers Part K Journal of Multi-body Dynamics, 224. (1) pp 83-101. (2010)

10. GOST 33788 Freight and passenger railcars. Methods of testing structural strength and dynamic performance (Moscow: Standartinform) p 41. (2016)

11. Lukin V V, Anisimov P S, Fedoseev Yu P, Wagons. General course (Moscow: Marshrut) p 424. (2004)

12. Rahimov R V, About measurements of vertical, longitudinal and lateral forces acting on the bogie side frame from the wheelset of a moving wagon Proc. of the Republican Scientific and Technical Conf. with the participation of foreign scientists "Resourcesaving technologies in railway transport" (Tashkent: Tashkent Railway Engineering Institute) pp 102-110. (2019).

13. Boronenko $\mathrm{Yu} \mathrm{P}$, Zhitkov $\mathrm{Yu} \mathrm{B}$, Rahimov $\mathrm{R} \mathrm{V}$, Measuring the loads acting on the bogie side frame from the wheelset of a moving wagon Proc. of the $14^{\text {th }}$ Int. Scientific and Technical Conf. "Rolling stock of the $21^{\text {st }}$ century: ideas, requirements, projects" (Saint Petersburg: Petersburg State Transport University) pp 121-124. (2019)

14. Ushkalov V F, Kostritsa S A, Sultan A V, Pasichnik S S, Dzichkovskiy E M, Fedorov $\mathrm{E} \mathrm{F}$, About the measurement of vertical forces at carrying out running dynamic tests of freight wagons Science and transport progress Bulletin of the Dnipro National University of Railway Transport. 30 pp 243-247. (2004)

15. Manashkin L A, Myamlin S V, Pis'mennyy E A, About the measurement of vertical forces in freight wagon bogies Science and transport progress Bulletin of the Dnipro National University of Railway Transport vol 5 pp (2004)

16. Ushkalov V F, Romen Yu S, Zavertalyuk A V, Ruban V I, About the issue of influence of longitudinal forces acting on the freight wagon bogie side frame, on its vertical dynamics Science and transport progress (2005). 
17. Boronenko Yu P, Rahimov R V, Dauksha A S Method of measuring vertical, longitudinal and lateral forces acting on side frame of bogie from axle box unit during wagon movement, and device for implementation thereof $R U 2724986 \mathrm{C} 1$ (JSC "NVTS "Vagony" Sankt-Petersburg, Russian Federation) publ. 29.06.2020 bull. (19) p 12 (2020).

18. Belyankin A V, Konovalov A I, Dorokhin D N, About experimental determination of the dynamic addition coefficient of non-sprung parts of a biaxial bogie of a freight wagon Proc. of the $14^{\text {th }}$ Int. Scientific and Technical Conf. "Rolling stock of the $21^{\text {st }}$ century: ideas, requirements, projects" (Saint Petersburg: Petersburg State Transport University) pp 203-205. (2019).

19. Rahimov R V, Boronenko Yu P, Measurements of vertical and lateral forces acting on the side frame of the bogie when the wagon is moving Proc. of the $\mathrm{X}$ Int. scientificpractical Conf. "Problems of Transport Safety" (Gomel: Belarusian State University of Transport) chapter (5) pp 115-117. (2020)

20. Orlova A M, Practical evaluation of the life test modes of the 18-9855 bogie side frames on the spatial loading test bench Wagons and Carriage Facilities 4. (40) pp 36-37 (2014). 